\title{
IS IT LEGAL YET?
}

\section{Social Issues in Computing and Teacher Education in Australia}

\author{
Anthony J. Jones \\ The University of Melbourne, Australia \\ E-Mail: A.Jones@unimelb.edu.au
}

Abstract: The widespread application of computers throughout the daily life of most people has brought about changes in the things we do and how we do them. Schools in many countries now make use of computer-based learning technologies at all levels of education, from kindergarten through secondary schooling to tertiary education. Use of computers for teaching and learning cannot be separated from effects that computerization has had on education and the wider community. Values, ethics and social issues related to computing represent one significant area of study for teachers and students. The purpose of this paper is to review the place given to computer related values, ethics and social issues in schools and teacher education.

Key words: Values; Ethics; Social issues; Teacher education

\section{INTRODUCTION}

When computers began to be used for teaching and learning in schools and universities there was little commercial educational software for sale. Teachers often used one of the small number of programming languages available to write, test and use educational software with their own students. Because those teachers who introduced computing into schools and developed their own software were enthusiasts, they met and corresponded with like-minded teachers. Inevitably this led to software being exchanged, and this was probably the origin of a software swapping culture that quickly developed in schools. Not only did a culture of software swapping develop among these computer-enthusiast teachers, it flourished and continued to exist for decades. 
What is the situation now? Articles about computer related ethics, values and social issues in mass circulation newspapers is one clue to community awareness of these matters. In September 2003 a daily Melbourne (Australia) newspaper published the four articles listed in Table 1.

Table 1. Sample of social issues articles from The Age newspaper

A week before it opened in US cinemas, a copy of the film The Hulk was available on illicit file-sharing networks. (Piracy, 2003)

The Australian government has introduced into parliament proposed anti-spam legislation that will penalize those convicted of illicitly spreading mass unsolicited electronic material up to AU $\$ 1.1$ million per day.(Cochrane, 2003)

Technology, like gambling and heroin, is addictive. We're driven or forced into buying new gadgets and constantly upgrading our technology. (Forno, 2003. p.6)

.. if online learning is becoming a method of semi-automated teaching, it could be big business. In Britain, e-learning already is. ... The British are driving e-learning into their schools by creating demand. (Wilson, 2003, p.10)

At first glance there might appear no obvious links between these articles, however there are at least two significant connecting factors. First, each article relates to an issue associated with the use (and misuse) of computers and computing applications. A second, and perhaps more worrying, connection between the articles is that they were all published in a single issue of the daily newspaper, albeit in a weekly IT supplement.

In addition to the four articles referred to above, the same edition of the IT supplement also contained an article on copyright and intellectual property, a book review about corporate IT security, and another on computer espionage, a case study of an Australian bank's approach to offshore outsourcing in order to reduce costs, an article on collaboration between Australian and US bodies responsible for emergency response to hacking, as well as an article detailing how dependent most people in developed countries are on computers for work, recreation, and at home. Each of these items also relates to computerization and associated implications for society.

This paper explores some of what has occurred between the swapping of software by pioneers of educational computing and the apparent high level of computer-related crime and associated issues in 2003. The theme that is explored concerns how ethics, values and social issues of computing have been incorporated or ignored in school and teacher education curricula.

\section{IN THE BEGINNING}

Norbert Wiener was probably the first person to write extensively on computers and ethics (Bynum, 2000). Long before computers were artifacts 
of everyday life Wiener was thinking and writing about the potential ethical and social issues arising from a range of newly developing technologies, including computerization (Wiener 1948, 1954).

In 1968 this author was teaching mathematics in a secondary school for boys. On an experimental basis he was permitted to introduce some computer programming to a class of high achievers. Possibly because it was part of mathematics, or possibly because he knew no better, the focus was entirely on learning the FORTRAN programming language to extend the mathematical experiences of the students. There is no record of any mention of computer-related values, ethics or social issues. The same remained true until the mid 1970s as the author continued to teach at a secondary school as well as teaching a computing subject to pre-service primary teachers.

Even before desktop computers appeared in large numbers in schools, teachers were teaching about possible ethical and social issues resulting from the newly developing computer technology. As early as 1982 articles about values and social issues were appearing in newly established computing journals for teachers (Finkel, 1983; Letellier, 1982). In a 1992 article in The Computing Teacher it was noted that "Teachers have told students about computer ethics for years" (Weller et al., 1992 p.20). The authors then referred to a series of articles from a 1984 issue of the same journal. These articles had titles such as "Ethics and computer use" (Gilliland \& Pollard, 1984), "A question of ethics" (Hannah \& Matus, 1984) and "Computers, kids and values" (Taffee, 1984).

It is impossible to accurately quantify the growth of publications that address some part of computer interrelated values, ethics or social issues. However there is no doubt these areas have become more significant and more widely publicized as computer use has spread throughout society. As a very simplistic measure, Table 2 lists the number of publications found in the ERIC database using search parameters (computer) AND (ethics). The number of publications decreases dramatically when the terms (education) OR (school) are added to the search parameters.

Table 2. "Computer ethics" publications listed in the ERIC database.

\begin{tabular}{ccc}
\hline Years & Number of items found & Cumulative total \\
\hline $1966^{4}-1969$ & 8 & 8 \\
$1970-1979$ & 45 & 53 \\
$1980-1989$ & 229 & 282 \\
$1990-1999$ & 460 & 742 \\
$2000-2003^{5}$ & 126 & 868 \\
\hline
\end{tabular}

${ }^{4}$ Beginning of ERIC electronic records.

${ }^{5}$ Searches conducted on 14 January 2004 at http://www.eduref.org. 
No matter what approach is used to analyze these data, it is evident that that very little has been published in this area. As noted above, when the search is limited to publications specifically about computer ethics and schools the number of publications is halved. A perusal of titles of remaining publications shows that many concern ethics for administrators or counselors and do not relate to classroom practice.

\section{PRACTICAL SOLUTIONS}

Faculties of education, school curriculum developers, ICT textbook authors, and ICT teachers do not collectively appear to give values and social issues relating to ICT a sufficient level of prominence. There are some curriculum references to values and social issues in school curricula, but often only at senior secondary levels rather than throughout all the levels of education and schooling in which students use or learn about ICT. As soon as primary school students begin to access electronic encyclopedias and the World Wide Web in their search for information for projects, they confront issues relating to intellectual property, copyright, acknowledgment and plagiarism. It would appear that by default many schools allow students to break laws relating to all of the above, In general this happens because teachers and parents focus on using technology and not the associated responsibilities and implications.

The case for students and teachers knowing about social and ethical issues associated with ICT throughout all subject areas of schooling might not appear as obvious or as strong as for learning about them in ICT specific subjects. However it can be argued that that it is vitally important for all students, not just those who study ICT, to have well developed understandings of ethical and legal issues relating to ICT use. It appears there is little evidence of this actually occurring on a consistent basis in primary and secondary schools. Some of the reasons for this are probably the same as those outlined above in relation to specialist ICT subjects and teachers. However a major cause is the over-emphasis on what can be done with technology and a corresponding lack of coverage of the consequences of doing things with technology. Often teachers and texts focus on the quite dramatic and valuable changes that can result from increased use of technology without giving sufficient consideration to the social, legal and ethical implications of these developments.

By the early 1980s articles were appearing in computing journals for teachers with titles such as "Crime in the classroom?" (Letellier, 1982) and "When is a pirate a thief?" (Finkel, 1983). Teachers were being informed of some of the ethical and legal issues relating to computing through journals 
and professional associations. However the quantity of articles published through the 1980s and well into the 1990s warning about the ramifications of copying software and other illegal and un-ethical practices suggest that it was a widespread problem in schools.

As school computing curricula became formalized, aspects of values, ethics and social issues were taught more consistently and in more organized ways. Related topics also became more prominent in textbooks. In Victoria, the first formal curriculum for a school computing subject was developed in the late 1970s and included "social implications" as one of the four areas of study. The most popular textbook for this subject (Woodhouse at al., 1982) included a chapter that introduced students to some of the ethical and social issues related to the technology of the time. It appears certain that one of the authors was approached to contribute to this book on the basis of personal interest and knowledge of computer-related social implications.

Teacher education has been slower than schools to accept the importance of computer related values, ethics and social issues. Until the mid 1990s, Australian pre-service teacher education courses were not required to include computing subjects. Then major credentialing authorities and employers demanded that every new teacher possess a range of computing skills and be aware of major technology related ethical and social issues.

In a pre-service subject for secondary IT teachers currently offered at The University of Melbourne, students undertake several projects and assessment tasks that involve them learning about social and ethical issues. One complicating factor is that many of the most appropriate techniques for teaching social and ethical issues at school level are based around strategies most employed by teachers of English and social studies, rather than teachers in the sciences or IT. Effective strategies include discussions and debates, role plays, research using a variety of sociological sources, essay writing, and a consideration of emotions and feelings. The majority of IT teachers have a background in science or business studies, and they find using such strategies to teach social and ethical issues more difficult than the technical aspects of their subjects.

For other secondary teachers in training, and for prospective elementary teachers, being able to apply humanities-based teaching strategies is less of a problem. Because they are not going to be specialized ICT teachers they rarely come into contact with concepts of technology related ethics, values, and social issues being classroom topics that should concern them. Far too many teachers who use ICT with students, but are not ICT teachers, never raise technology-related legal and ethical issues with students, even though schools throughout the world appear to have acceptable use policies that students and their parents are required to agree to and sign. 
However school acceptable use policies have failed to go far enough. Usually they are little more than an attempt to safeguard a school from legal charges that might arise from students who infringe copyright or ethical statutes while using school computers. Rarely is there an education program for students and parents that complements the signing of an acceptable use agreement. For classroom teachers the major problem relates to students plagiarizing material from an electronic resource and failing to acknowledge the source and ownership of ideas and images that are used in assignments.

The National Educational Technology Standards project (NETS, 2002) includes ideas for including "analyzing legal, moral, and ethical dilemmas" within teacher education. Not only are these issues raised with at these levels, but quite specific activities and roles are designated for teacher educators and the beginning teachers. Although it might appear elsewhere, a major weakness of this section is that the vignettes used focus on out-ofclassroom situations. While this is understandable because the section is about professional preparation, there is no link to classroom teaching about the legal, moral and ethical dilemmas students encounter in their daily lives.

Similar comments apply to the "ICT skills test" (TTA, 2003) all teachers in-training in England must pass before they gain accreditation to teach. This test aims to guarantee that new teachers have an appropriate grounding in basic ICT skills. Again, as with the NETS material, there is no statement informing new teachers that it is the duty of every teacher to be aware of, to uphold personally and professionally, and to ensure that students do not breach laws concerning legal, moral and ethical issues relating to all educational technologies, and to computing in particular.

\section{CONCLUSION}

When computers were rare in commerce and industry, and did not exist in schools, what little educational interest there was focused on the potential of computers for relieving humans of mundane, difficult, or dangerous tasks. Most people did not know what computers were doing, because much of it was related to military applications and was restricted. It was only when computers became smaller, simpler and generally available that they became associated with crime and social issues such as privacy and replacing people in employment. Today teachers and students use computer technology as a normal part of the education process, and there is an obvious need to know about the effects of technology as well as the applications. 


\section{REFERENCES}

Bynum, T., 2000, A very short history of computer ethics. (September 17, 2003); http://apa.udel.edu/publications/newsletters/v99n2/computs/index.asp.

Bynum, T., 2001, Computer Ethics: Basic Concepts and Historical Overview, in: The Stanford Encyclopedia of Philosophy, E. Zalta, ed., (September 17, 2003); http://plato.stanford.edu/archives/win2001/entries/ethics-computer/.

Cochrane, N., 2003, Government hopes to send message with anti-spam bill. The Age, 23 September. Next, p. 3.

Finkel, L., 1983, When is a pirate a thief? Electronic Learning, 3(2):26-28.

Forno, R., 2003, Hooked on high-tech. The Age, 23 September. Next, p. 6.

Gilliland, K. \& Pollard, M., 1984, Ethics and computer use. The Computing Teacher. 12(1): 19-23.

Hannah, L. \& Matus, C., 1984, A question of ethics. The Computing Teacher, 12(1):11-14.

Letellier, L., 1982, Crime in the classroom? Electronic Learning, 1(3):42-44, 51.

Marsh, M., 1998, Piracy, pornography, plagiarism, propaganda, privacy: Teaching children to be responsible users of technology. (September 17, 2003); http://www.computerleaming.org/articles/Ethics98.htm.

NETS, 2002, Analyzing legal, moral and ethical dilemmas. (February 14, 2004): http://cnets.iste.org/teachers/.

Piracy, 2003, Piracy becoming a monster of a problem. The Age, September 23. Next, p. 3.

Taffee, S., 1984, Computers, kids and values. The Computing Teacher, 12(1):15-18.

TTA, 2003, ICT skills test. Teacher Training Agency. (February 14, 2004): http://www.tta.gov.uk/.

Weller, H., Repman, J., Rooze, G. \& Parker, R., 1992, Students and computer ethics: An alternative to preaching. The Computing Teacher, 20(1): 20-22.

Wiener, N., 1948, Cybernetics: or Control and Communication in the Animal and the Machine. Technology Press: Cambridge, MA.

Wiener, N., 1954, The Human Use of Human Beings: Cybernetics and Society. 2nd ed., Doubleday: New York.

Wilson, E., 2003, Music e-learning sounds a positive note for online hopes. The Age, September 23. p.10.

Woodhouse, D., Johnstone, G., \& McDougall, A., 1982, Computer Science. John Wiley \& Sons: Brisbane. 